Article

\title{
Study on Friction Behavior of Ferroalloy and Wet Granulation Sulfur under Low Normal Load Conditions
}

\author{
Haoyuan Dai ${ }^{1,2,3}$, Jianchun Fan ${ }^{3, *}$, Yanqiu Yu ${ }^{3,4}$, Li Sun ${ }^{3}$, Zhibin $\mathrm{Hu}^{3}$ and Jiancun Gao ${ }^{1,2}$ \\ 1 School of Safety Engineering, Beijing Institute of Petrochemical Technology, Beijing 102617, China; \\ daihaoyuan@bipt.edu.cn (H.D.);0020180015@bipt.edu.cn (J.G.) \\ 2 Beijing Academy of Safety Engineering and Technology, Beijing 102617, China \\ 3 College of Safety and Ocean Engineering, China University of Petroleum-Beijing, Beijing 102200, China; \\ yuyanqiu_puguang@hotmail.com (Y.Y.); 0620181003@bipt.edu.cn (L.S.); \\ 2015314032@student.cup.edu.cn (Z.H.) \\ 4 Sinopec Dazhou Natural Gas Purification Plant, Puguang 636150, China \\ * Correspondence: daihaoyuan123@163.com; Tel.: +86-151-0114-8803
}

Received: 16 October 2019; Accepted: 26 November 2019; Published: 28 November 2019

check for updates

\begin{abstract}
To study the friction behavior of ferroalloy and wet granulation sulfur under low normal load conditions, a series of experiments were performed using a homemade rotating test apparatus. Scanning electron microscopy with an energy dispersive spectrometer (SEM-EDS) and X-ray diffraction (XRD) were utilized to examine the friction products. The experimentally monitored friction coefficient data were used to develop a finite element model to simulate the temperature field and a theoretical model to calculate the flash temperature of the contact area of the friction surface. The experimental, simulation, and theoretical results showed that the flash temperature of the friction surface is much higher than the average temperature of the friction surface and allows the reaction of iron and sulfur to form iron-sulfide compounds.
\end{abstract}

Keywords: ferroalloy; wet granulation sulfur; low normal load; friction temperature; mechanochemistry

\section{Introduction}

During the transportation of wet granulation sulfur, many steel transmission components such as the bucket wheel stacker-reclaimer, are exposed to sulfur powder. Friction between the sulfur powder and steel equipment may cause fire accidents if not detected immediately [1,2]. It is necessary to investigate the friction behavior of ferroalloy and wet granulation sulfur under low normal load conditions to improve operation conditions to avoid this type of accident.

Few studies have systematically explored the friction behavior of ferroalloy and wet granulation sulfur under low normal load conditions. Cai [3] and Fu [4] et al. have investigated the static accumulation behavior during the friction process of sulfur and stainless steel. It is concluded that static electricity will be generated during the friction between sulfur and stainless steel. The presence of moisture will lead to a significant reduction in accumulated static electricity. Jiang [5] and Chin [6] et al. have investigated the mechanochemical reaction of sulfur and reduced iron powder in an anaerobic environment with the help of high-energy planetary ball mill. It is concluded that during the friction process of iron and sulfur the FeS and $\mathrm{FeS}_{2}$ are produced and the final friction products are different with different proportions of iron powder and sulfur dust in the starting materials.

The friction ignition mechanism of wet granulation was preliminary investigated in our previous work [7]. However, less attention has been paid to the friction process under low normal load conditions. Although the final friction products have been analyzed, the changes of products during 
the friction process have not been studied. The formation mechanism of iron and sulfur compounds in the friction process was put forward, but it remains unclear whether the temperature distribution of the friction surface during the friction process is sufficient to allow formation of iron-sulfide compounds. To simulate the friction situation in the field, friction pairs were matched with a ring-on-disk type, so that some friction products will release the friction surface during the friction process, which affects analysis of the friction products. In addition, the hole used for temperature detection was not completely sealed, but allowed outside cold air to enter, resulting in underestimating the actual temperature.

For the study of friction temperature, scholars are concerned about the flash temperature and the average temperature of the frictional surface. In 1937, when F. P. Bowden studied the surface temperature of solid friction, it was suggested that the friction temperature of the contact point in the case of sliding friction could be very high, which could actually lead to the melting of the metal [8]. In 1950, Bowden mentioned that when high-speed friction is carried out on metals with unsmooth surface with higher melting point, local instantaneous high temperature will occur on the friction surface, sometimes the temperature can reach $1000^{\circ} \mathrm{C}$ [9]. In 1959, Archard first proposed the concept of flash temperature and also gave the formula for calculating the frictional flash temperature [10]. In 1963, Blok investigated the history of the development of the flash temperature concept [11]. Abdel-Aal systematically elaborated the flash temperature theory [12]. A transient flash temperature model was developed based on a fast Fourier transform method. An analytical expression for the heat partition function was obtained by Gao. [13]. Shi and Yao established a pin-on-disk temperature field model via the finite element method, and the steady-state temperature distributions for the pin and the disk [14]. Chang and Peng have investigated the evolutions of the coefficient of friction (COF), temperature rise, and wear characteristics under different contact loads by a series of experiments [15]. Wang investigated the high-temperature tribological behavior of the Ti-22Al-25Nb (at. \%) orthorhombic alloy with lamellar O microstructures [16]. Some scholars have studied the contact problems involved in the friction process of rough surface and put forward different contact models [17-20]. The main weakness of the above-mentioned test specimens is their inability to accurately measure the temperature of the friction surface. The specimen geometries of the existing test specimens cannot keep the friction products stay in the friction surfaces. Although the existing literature has carried out a lot of research on the friction flash temperature and the average temperature of the friction surface, there is no literature to study the change of the flash temperature and the average temperature of the friction surface during the ferroalloy-sulfur friction process. It is difficult to accurately measure the friction temperature field and flash temperature through experiments. Therefore, a new test specimen with improved structure, a finite element model to simulate the temperature field, and a theoretical model to calculate the flash temperature of the friction surface during the friction process by using the experimentally monitored friction coefficient data were needed to be developed to study the friction behavior of ferroalloy and sulfur.

In this study, a series of experiments with different friction duration were performed under low normal loads. New test specimens with improved structure were used in the experiments. The friction products were characterized using SEM-EDS and XRD analyses. The experimentally monitored friction coefficient data were used to develop a finite element model to simulate the temperature field during the friction process. Additionally, a theoretical model based on flash temperature theory [8-13] and the "GW (Greenwood-Williamson)" contact model [17-20] was developed to calculate the flash temperature of the friction surface. The research results prove that under low load conditions, long-term ferroalloy-sulfur friction can still lead to the formation of ferrous sulfide, and there is a risk of fire accidents caused by spontaneous combustion of ferrous sulfide, which can be used to guide the development of on-site prevention and control measures. The results of experimental and theoretical analyses of the friction behavior of ferroalloy and wet granulation sulfur under low normal load conditions provide the theoretical basis to avoid fire accidents of sulfur caused by friction. 


\section{Methods}

\subsection{Experiment Methods}

The scheme of the test apparatus, the test procedures, the pretreatment process of the friction specimens, and the characterization methods of the friction products can be referred in Ref. [7]. The distinction is that new test specimens with improved structure were used in this work. The structures of the new test specimens are illustrated in Figure 1.

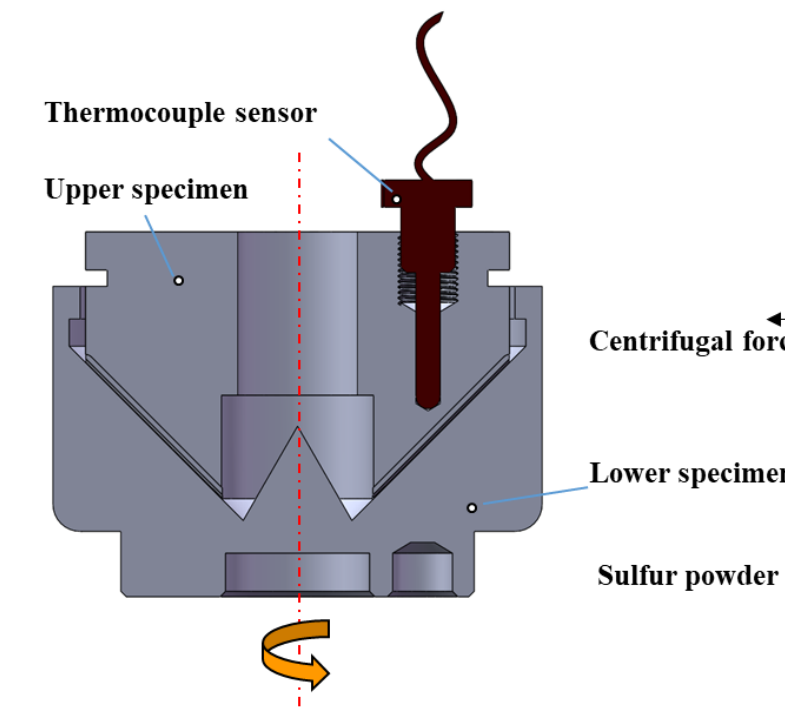

(a) (b)

Figure 1. Schematic diagram of friction specimens (a) and moving trend of sulfur powder during the friction process $(\mathbf{b})$.

As shown in Figure 1, the upper end of the lower specimen is a taper hole, and the lower end of the upper specimen is a taper there is matched with the upper specimen. The cone design of the friction surface ensures the circulatory movement of sulfur dust, liquefied sulfur, or friction products on the friction surface under the driving force of the upper specimen. The rotating particles will tend to move toward the outer edge under the centrifugal force. However, under the combined action of gravity and the acting force of the friction surface, the position of the particles will stabilize near a certain location. In this way, sulfur can distribute relatively evenly on the friction surface for full reaction with the friction specimens during the friction process. The integrated design of the lower specimen ensures that the friction medium and friction products remain in the friction specimen. The thermocouple is mounted directly on the upper specimens to ensure that the temperature measuring hole is sealed for more accurate temperature measurement. The distance between the friction surface and the thermocouple is about $1 \mathrm{~mm}$, sufficiently close for measurement. The internal diameter of the friction face is $26 \mathrm{~mm}$ and the outside diameter of the friction face is $78 \mathrm{~mm}$.

To study the friction behavior of ferroalloy and wet granulation sulfur under low normal load conditions, experiments with different friction duration were performed under a low normal load of $210 \mathrm{~N}$. The rotational speed of lower specimen was set as $200 \mathrm{rpm}$ based on the specimen geometry and the field conditions. The details of the test setup are shown in Table 1. 
Table 1. Setup of the test.

\begin{tabular}{ccccccc}
\hline $\begin{array}{c}\text { Test } \\
\text { Duration }\end{array}$ & $\begin{array}{c}\text { Normal } \\
\text { Load }\end{array}$ & $\begin{array}{c}\text { Rotational } \\
\text { Speed }\end{array}$ & $\begin{array}{c}\text { Specimen } \\
\text { Material }\end{array}$ & Friction Medium & $\begin{array}{c}\text { Ambient } \\
\text { Temperature }\end{array}$ & $\begin{array}{c}\text { Ambient } \\
\text { Relative } \\
\text { Humidity }\end{array}$ \\
\hline $0.5 \mathrm{~h}$ & $210 \mathrm{~N}$ & $200 \mathrm{rpm}$ & $1045 \mathrm{steel}$ & $\begin{array}{c}\text { Sulfur powder with } \\
2 \% \text { water, } 4 \mathrm{~g}\end{array}$ & $20 \pm 5{ }^{\circ} \mathrm{C}$ & $20 \% \pm 5 \%$ \\
\hline $1.0 \mathrm{~h}$ & $210 \mathrm{~N}$ & $200 \mathrm{rpm}$ & 1045 steel & $\begin{array}{c}\text { Sulfur powder with } \\
2 \% \text { water, } 4 \mathrm{~g}\end{array}$ & $20 \pm 5{ }^{\circ} \mathrm{C}$ & $20 \% \pm 5 \%$ \\
\hline $1.5 \mathrm{~h}$ & $210 \mathrm{~N}$ & $200 \mathrm{rpm}$ & 1045 steel & $\begin{array}{c}\text { Sulfur powder with } \\
2 \% \text { water, } 4 \mathrm{~g}\end{array}$ & $20 \pm 5{ }^{\circ} \mathrm{C}$ & $20 \% \pm 5 \%$ \\
\hline $2.0 \mathrm{~h}$ & $210 \mathrm{~N}$ & $200 \mathrm{rpm}$ & 1045 steel & $\begin{array}{c}\text { Sulfur powder with } \\
2 \% \text { water, } 4 \mathrm{~g}\end{array}$ & $20 \pm 5{ }^{\circ} \mathrm{C}$ & $20 \% \pm 5 \%$ \\
\hline
\end{tabular}

\subsection{Theoretical Methodology}

\subsubsection{Frictional Heat Calculation}

Frictional heat is the main heat source in this sulfur-iron friction system. As indicated in Figure 2, the friction specimens were assumed to have a uniform contact, so that the normal pressure and friction coefficient of each region were the same. The rate of frictional heat generation is given by Equation (1) [18].

$$
q=\mu \times F_{n} \times v_{s},
$$

where $\mu$ is the friction coefficient, $F_{n}$, the asperity contact pressure, and $v_{S}$, the sliding speed.

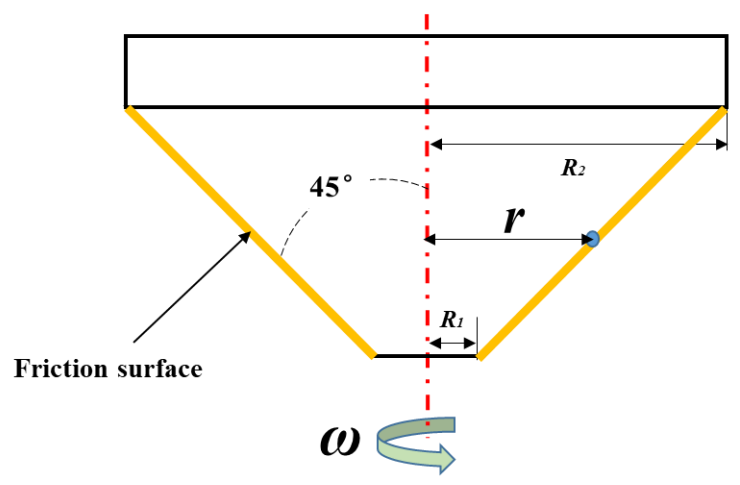

Figure 2. Frictional heat at different locations.

$F_{n}$ can be obtained by Equations (2) and (3).

$$
\begin{gathered}
F_{n}=\frac{F}{A}, \\
A=\sqrt{2} \pi \times\left(R_{2}{ }^{2}-R_{1}{ }^{2}\right),
\end{gathered}
$$

where $F$ is the normal load of the friction surface, $A$, the area of the friction surface, $R_{1}$, the inner radius of the contact surface, and $R_{2}$, the outer radius of the contact surface.

$v_{s}$ is given by Equation (4).

$$
v_{s}=r \times \omega,
$$

where $\omega$ is the rotational speed of the lower specimen, and $r$, the rotation radius of the lower specimens.

The friction of ferroalloy and wet granulation sulfur is an extremely complex process, and changes in the physicochemical properties of sulfur, or the morphology and composition of the friction surface will cause a change in the friction coefficient [21-23]. Therefore, the friction coefficient cannot be considered a fixed value for the calculation of frictional heat, but should instead be calculated according 
to the monitored friction torque during the test process. The relationship between friction torque $M$ and friction coefficient $\mu$ is given by Equation (5).

$$
M=\int_{R 1}^{R 2} r \times \mu \times F_{n} \times 2 \times \pi \times r \times \sqrt{2} d r .
$$

It can be obtained from Equation (5).

$$
\mu=\frac{3 \times M}{2 \sqrt{2} \times \pi \times\left(\mathrm{R}_{2}{ }^{3}-\mathrm{R}_{1}{ }^{3}\right) \times F_{n}}
$$

Substituting Equations (2)-(6) into Equation (1) yields

$$
q=\frac{3 \times M}{2 \sqrt{2} \times \pi\left(\mathrm{R}_{2}{ }^{3}-\mathrm{R}_{1}{ }^{3}\right)} \times r \times \omega
$$

The frictional heat is mainly absorbed by the friction specimens and the friction medium sulfur, assuming the even distribution of sulfur dust on the friction surface. The heat absorption rate of sulfur is given by Equation (8) [24].

$$
q_{\text {sulfur }}=\frac{c_{\text {sulfur }} \times m_{\text {sulfur }}}{A} \bullet \frac{\partial T_{\text {sulfur }}}{\partial t}
$$

where $c_{\text {sulfur }}$ is the specific heat of sulfur, $m_{\text {sulfur }}$, the total mass of sulfur, $T_{\text {sulfur }}$, the temperature of sulfur, and $t$, time. Then, the heat absorption rate of the friction specimens is given by Equation (9).

$$
q_{\mathrm{s}}=q-q_{\text {sulfur }}
$$

\subsubsection{FEM for Numerical Simulation of Temperature Field of the Friction Specimens}

Assuming that the sulfur dust is distributed evenly on the friction surface, the temperature of the friction medium is the same as that of the friction surface. The temperature field distribution of the friction specimens can be considered to follow the heat transfer process from a surface heat source to a three-dimensional geometry (upper and lower friction specimens). The governing equation for the heat propagation inside the specimens is [25]:

$$
\rho c \frac{\partial T}{\partial t}-\nabla \cdot\left(K_{1} \nabla T\right)=q_{s}
$$

where $T$ is the temperature, $t$, time, $K_{1}$, the heat transfer coefficient of the specimen material, and $c$, the specific heat of the specimen material. Generally, it is difficult to obtain the analytical solution of the temperature distribution of the specimen. Instead, the temperature distribution must be determined by

\begin{tabular}{|c|c|c|c|c|c|}
\hline Materials & Thermal Conductivity & Specific Heat & Friction Coefficient & Normal Loads & $\begin{array}{c}\text { Initial } \\
\text { Temperature }\end{array}$ \\
\hline $\begin{array}{l}1045 \text { steel } \\
\text { Sulfur } \\
\text { Air }\end{array}$ & $\begin{array}{l}\text { According to materials } \\
\text { library of COMSOL, } \\
\text { change with temperature }\end{array}$ & $\begin{array}{l}\text { According to materials } \\
\text { library of COMSOL, } \\
\text { change with temperature }\end{array}$ & $\begin{array}{l}\text { Calculated according } \\
\text { to the monitored } \\
\text { friction torque }\end{array}$ & $210 \mathrm{~N}$ & $15^{\circ} \mathrm{C}$ \\
\hline
\end{tabular}
numerical simulation. A three-dimensional model is set up using COMSOL Multiphysics (Version 4.2). The geometry of the simulated specimen is the same as that of the experimental specimen with simplified structure. The parameter settings of the numerical simulation are shown in Table 2. The established simulation model is shown in Figure 3.

Table 2. Parameter settings. 


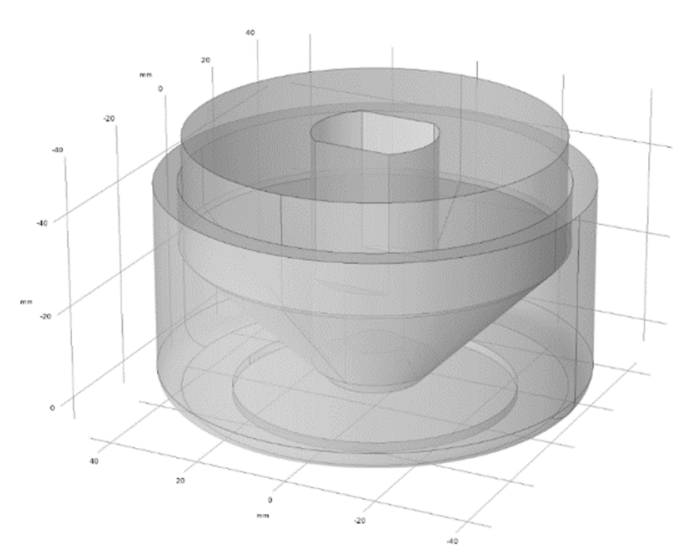

Figure 3. Simulation model of friction specimens.

\subsubsection{Theoretical Model to Calculate Flash Temperature}

In the friction process, the flash temperature resulting from the friction between asperities of the friction specimens has a great influence on the overall friction behavior of ferroalloy and wet granulation sulfur. The friction flash temperature can be obtained according to the flash temperature calculation model (Blok) [10-13,20]. The maximum temperature that increases on the sliding friction surface is the flash temperature, and is described by Equation (11).

$$
T_{\max }=\frac{1.6 r_{1} \Omega \mu F_{n}}{\rho c} \sqrt{\frac{v_{s} l}{K_{1}}}
$$

where $r_{1}$ is the ratio of friction heat transferred to the asperities, $\Omega$, the surface contact coefficient, and $l$, the width of the contact area of the asperities.

Generally, the profile height distribution of the actual surface conforms to a Gaussian distribution $[19,26]$. Based on the tribology principle and a Gaussian contact model [17-20], the surface contact coefficient $\Omega$ can be expressed as Equation (12).

$$
\Omega=\frac{R}{\left(h^{*}-d^{*}\right) \sigma \int_{d^{*}}^{\infty} \frac{1}{\sigma(2 \pi)^{\frac{1}{2}}} \exp \left(-\frac{\left(h^{*}\right)^{2}}{2}\right) d h} .
$$

It means the contact coefficient of the asperity with feature height $h^{*}$, the probability of this situation is

$$
\int_{d^{*}}^{\infty} \frac{1}{\sigma(2 \pi)^{\frac{1}{2}}} \exp \left(-\frac{\left(h^{*}\right)^{2}}{2}\right) d h
$$

where $R$ is the mean radius of asperities, $d^{*}$, the feature distance of centreline, $\sigma$, the standard deviations, and $h$, the height of the asperities.

\section{Results}

\subsection{Measured Temperature near the Friction Surface}

The temperatures on the near friction surface and the friction torque were recorded during the test. The sampling frequency was $1 \mathrm{~Hz}$. The temperature variation curves are shown in Figure 4. 


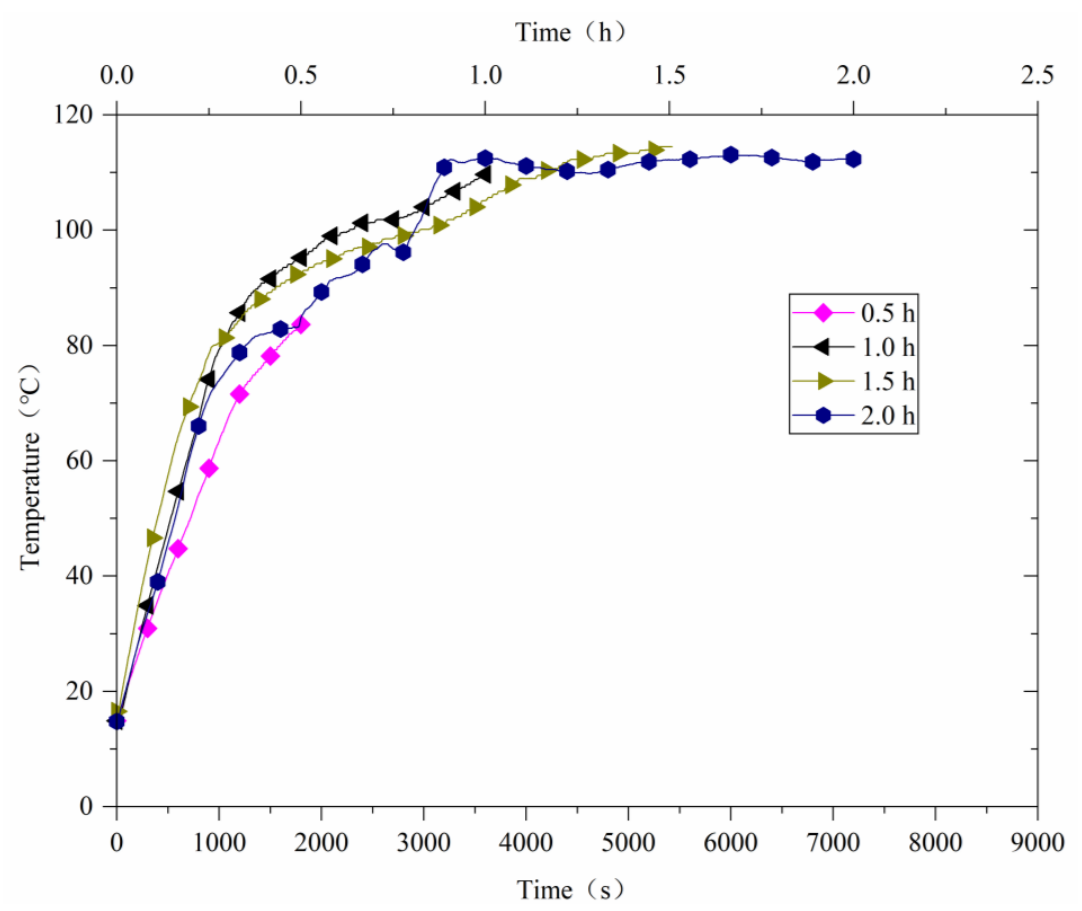

Figure 4. Temperatures near friction surface under different friction time.

As indicated in Figure 4, for the tests with the same working conditions but different friction duration, the temperature changes in the near friction surface showed little change during the same friction period. The comparative analysis of the friction products obtained during different friction durations can be used to understand the changes of friction products and the friction behavior mechanism of ferroalloy and wet granulation sulfur.

\subsection{Tested Specimens and the Analysis of Friction Products}

The tested specimens and friction products are shown in Figure 5.

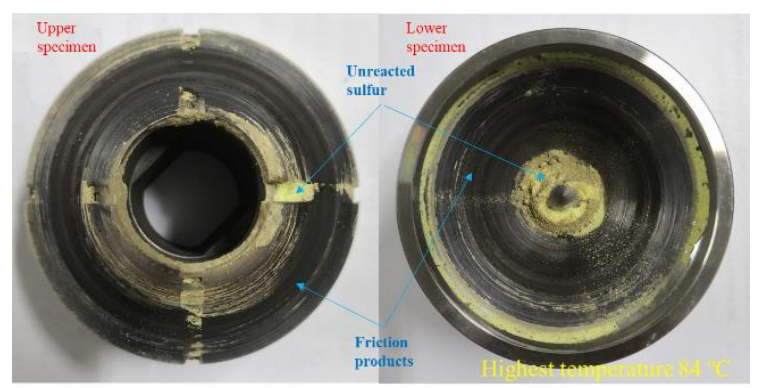

(a)

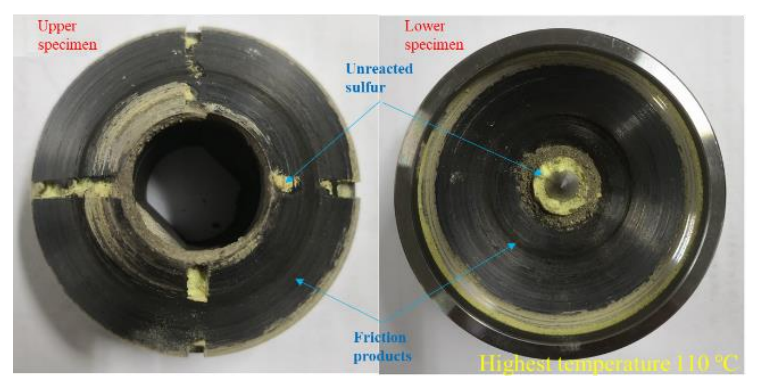

(b)

Figure 5. Cont. 


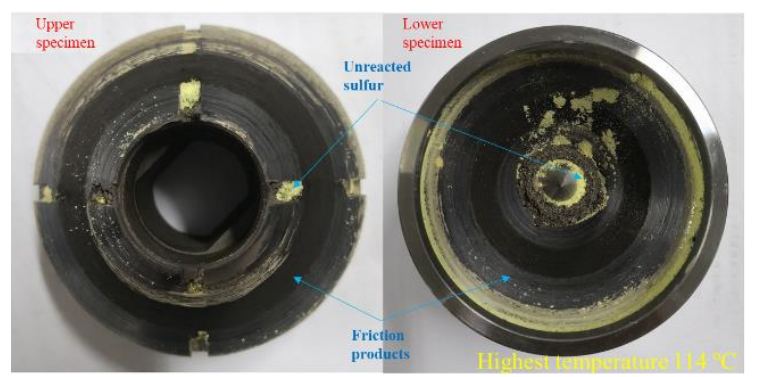

(c)

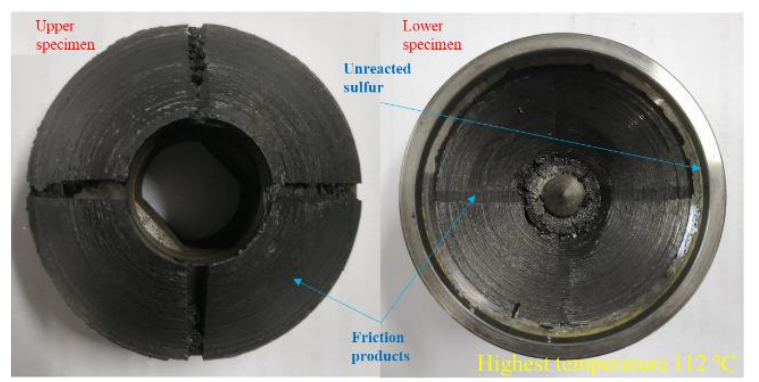

(d)

Figure 5. Photographs of tested specimens and friction products with different friction durations $(0.5 \mathrm{~h} \mathrm{(a)}, 1.0 \mathrm{~h} \mathrm{(b)}, 1.5 \mathrm{~h} \mathrm{(c)}$, and $2.0 \mathrm{~h}(\mathbf{d}))$.

As indicated in Figure 5, with increased friction time, the amount of black friction products gradually increased and the thickness of the friction product layer on the specimen surface after friction increased gradually. For a friction duration of $0.5 \mathrm{~h}$, a small amount of friction products were produced, with unreacted sulfur dust the primary material on the friction surface. Compared with the experiment with a friction duration of $0.5 \mathrm{~h}$, for friction lasting $1.0 \mathrm{~h}$, more black friction products were generated, but a large amount of unreacted sulfur dust was still present on the friction surface. For $1.5 \mathrm{~h}$ of friction, amount of black friction products further increased, with some unreacted sulfur dust remaining on the friction surface. For friction of $2.0 \mathrm{~h}$, the friction surface was covered with black friction products, and only trace amounts of yellow sulfur dust remain.

\subsubsection{SEM-EDS Analysis of Friction Products}

The microstructure and composition of friction products were analyzed by using SEM-EDS (FEI Quanta 200 SEM, FEI Company, Hillsboro, OR, United States) methods. The results are shown in Figure 6.

As shown in Figure 6, the iron contents of the samples subjected to friction duration of 0.5, 1.0, 1.5 , and $2.0 \mathrm{~h}$ were measured as $45.15 \%, 40.65 \%, 42.74 \%$, and $39.10 \%$ (atomic fraction) respectively. These were relatively high atomic fractions of iron, which was inconsistent with the conclusion in the 2nd paragraph of Section 3.2 (tested specimens and the analysis of friction products). This might be because the SEM-EDS analysis was performed on the black portion of the friction product. However, it was obvious that after $2.0 \mathrm{~h}$, the friction products contained a lower amount of iron, likely due to sulfur melting after $2 \mathrm{~h}$ of friction and the addition of more unreacted molten sulfur to the black friction product. The molten sulfur might be more likely to mix with black friction products, as after $2 \mathrm{~h}$ of friction, the largest amount of sulfur melting was observed. The data presented in Figure 6 show that the friction products contained iron and sulfur, but did not reveal the composition of these products. Therefore, $\mathrm{XRD}$ analysis on the basis of SEM-EDS was required to determine the composition of friction products. 


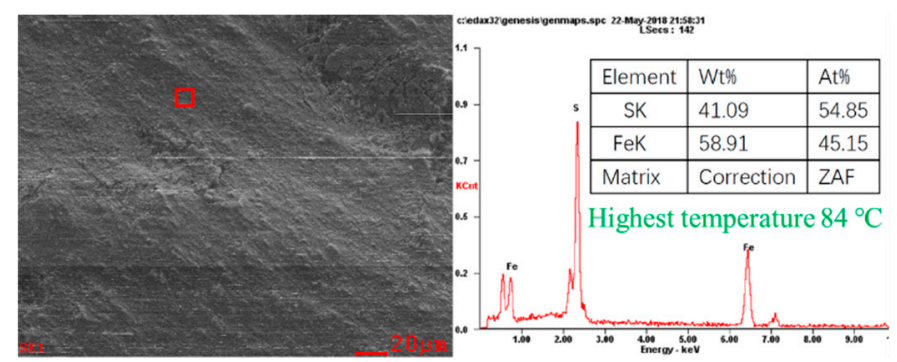

(a)

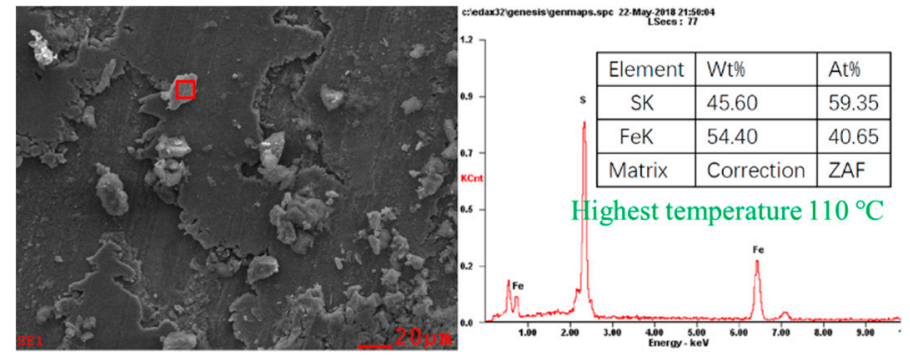

(b)

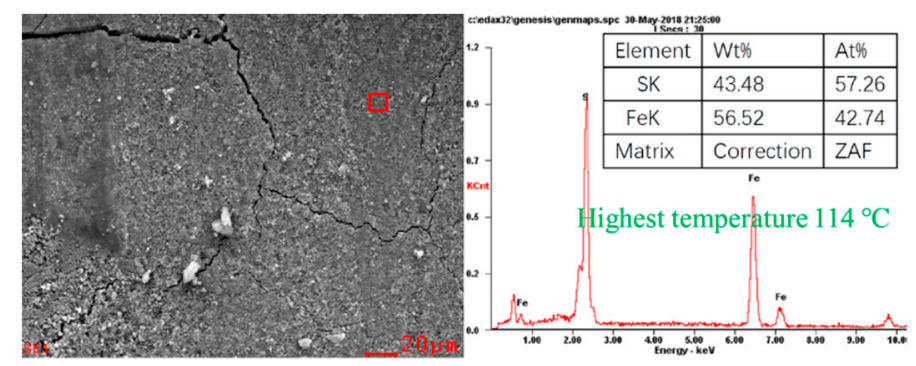

(c)

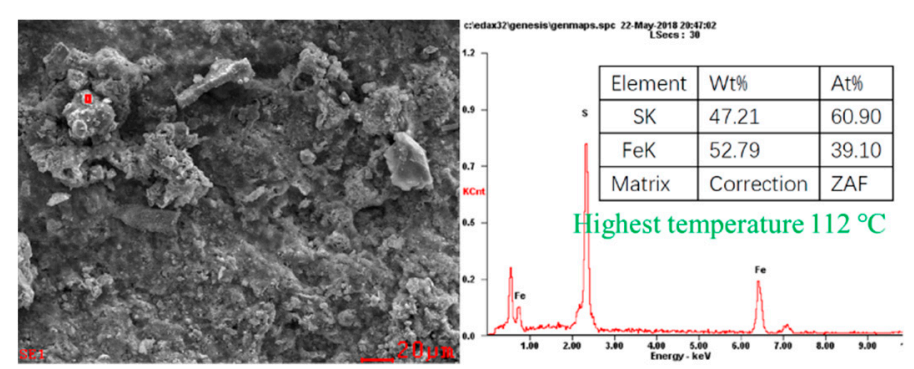

(d)

Figure 6. SEM-EDS results of friction products on the surface of tested specimens with different friction duration $(0.5 \mathrm{~h}(\mathbf{a}), 1.0 \mathrm{~h}(\mathbf{b}), 1.5 \mathrm{~h}(\mathbf{c})$, and $2.0 \mathrm{~h}(\mathbf{d}))$.

\subsubsection{Crystal Phase Analysis of Friction Products}

The composition of the friction products were characterized by using the XRD (D8 ADVANCE Specifications, Bruker Corporation, Karlsruhe, Germany) method. The XRD pattern is shown in Figure 7. 


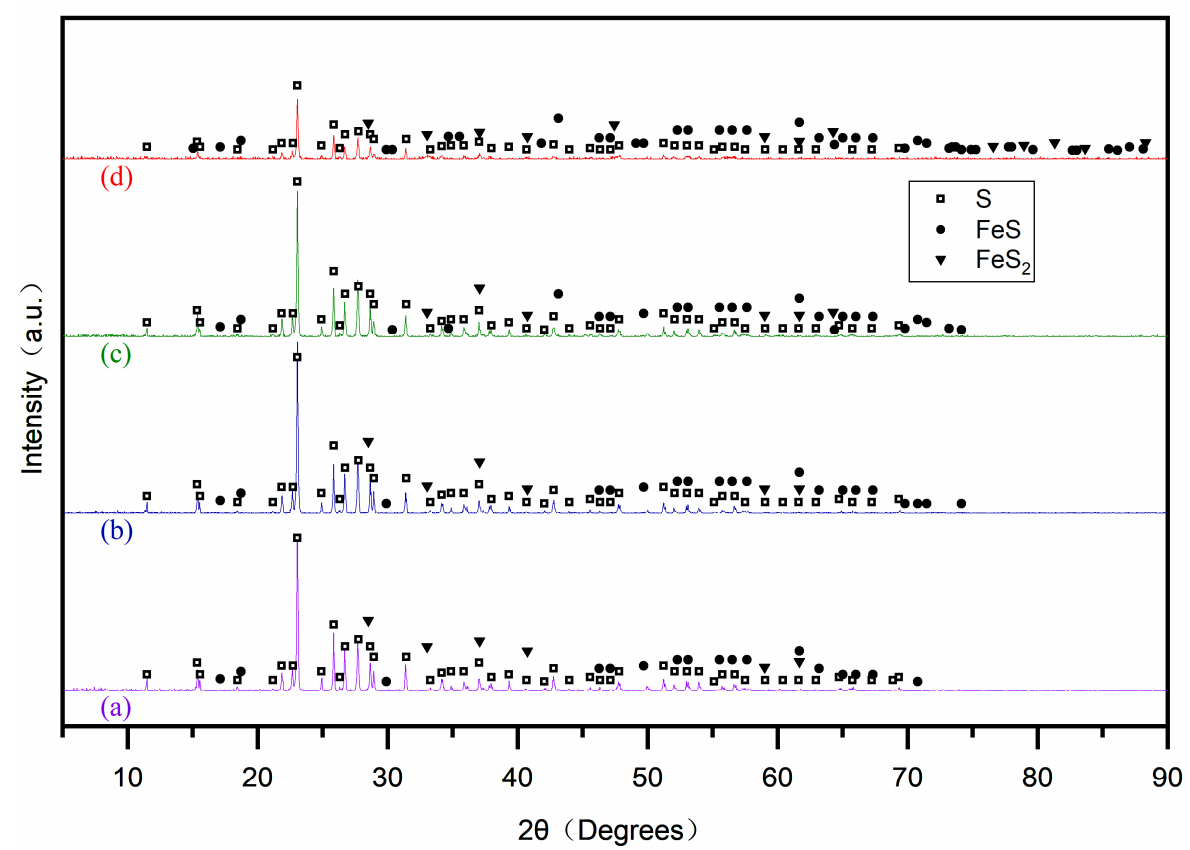

Figure 7. X-ray diffraction patterns of the friction products with different friction durations $(0.5 \mathrm{~h} \mathrm{(a),}$ $1.0 \mathrm{~h} \mathrm{(b)}, 1.5 \mathrm{~h}(\mathbf{c})$, and $2.0 \mathrm{~h}(\mathrm{~d}))$.

Figure 7 shows that the black friction products obtained after different friction durations were basically the same. Sulfur was the main component of the black friction product produced during a short friction period (no more than $2 \mathrm{~h}$ ). The friction products also contained small amounts of iron sulfide compounds $\left(\mathrm{FeS}\right.$ and $\mathrm{FeS}_{2}$ ). With increased friction time, the content of iron sulfide compounds increased gradually, while the content of unreacted sulfur decreased gradually.

\subsection{Temperature Field Distribution of Friction Specimen}

The distributions of the internal temperature field of the friction specimens after $2.0 \mathrm{~h}$ of friction were determined and are shown in Figure 8. The initial temperature was $15^{\circ} \mathrm{C}$, the rotating speed was $200 \mathrm{rpm}$, and the normal load was $210 \mathrm{~N}$, which was the same to that in experimental measured.

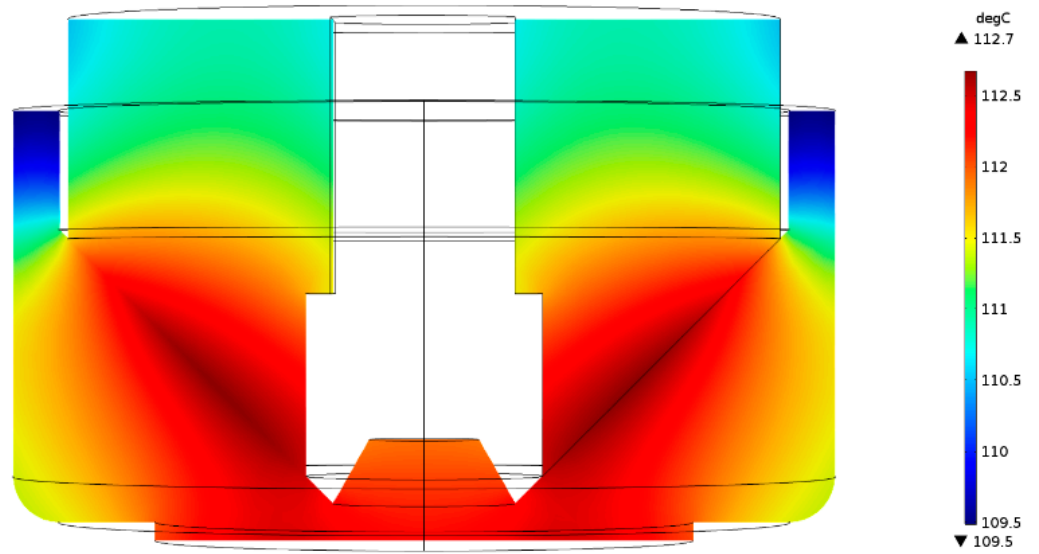

Figure 8. Internal temperature distribution of friction specimens after $7200 \mathrm{~s}$ friction.

As shown in Figure 8, the internal temperature of the friction specimens reached $112.7^{\circ} \mathrm{C}$ after $7200 \mathrm{~s}$ of friction. The temperature of the friction specimens varied with location, with the higher temperature on the friction surface and gradually decreasing temperature with increasing distance 
from the friction surface. Additionally, the temperatures differed at different positions on the friction surface, with the temperature on the edge of the friction surface lower than the temperature in the middle. This is due to increased heat generated by friction with increased radius, but greater heat dissipation at the outer edge of the friction surface due to its direct contact with air. The temperature at the near friction surface and the friction surface were compared, and the results are shown in Figure 9.

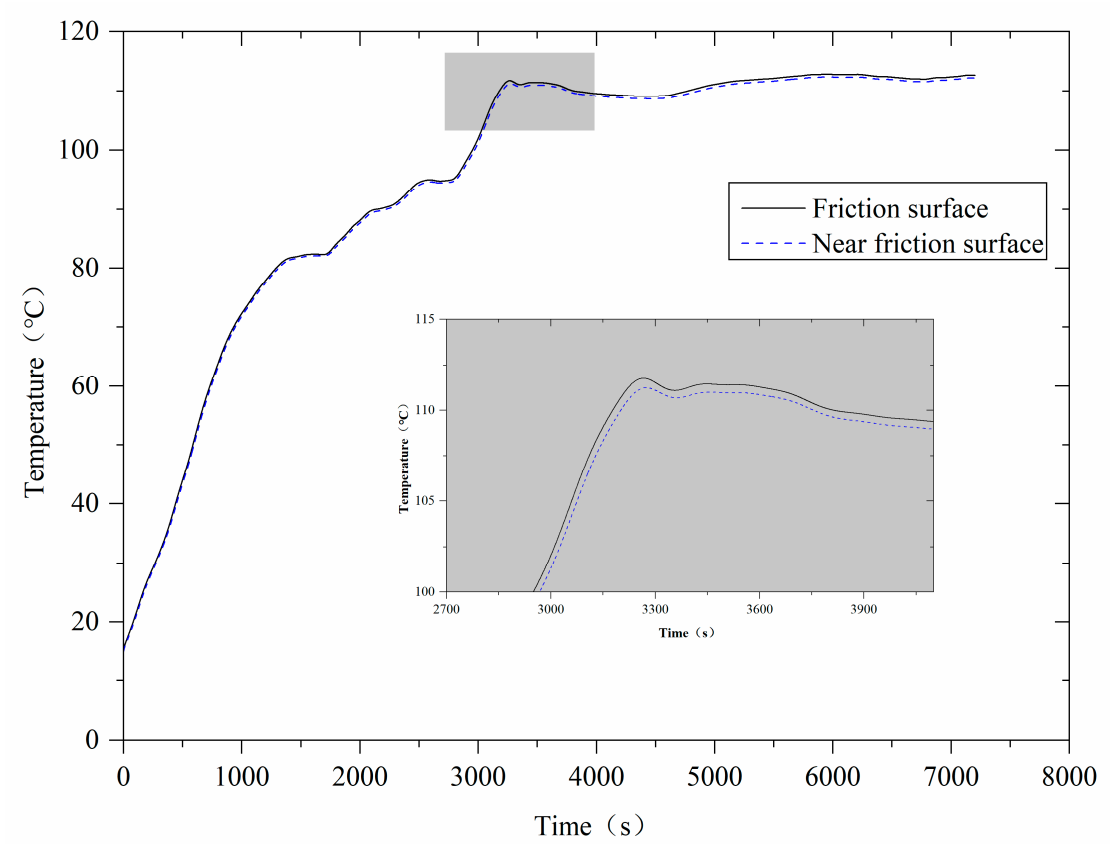

Figure 9. Temperature change of friction surface under temperature measuring point and temperature measuring point (near friction surface).

It can be seen from the data presented in Figure 9 that the temperature of the friction surface below the temperature measurement point exhibited basically the same temperature change curve as the temperature measurement point. The temperature of the friction surface was slightly higher than that of the temperature measurement point, but this temperature difference was not large (less than $2{ }^{\circ} \mathrm{C}$ ), indicating that monitoring the temperature at the temperature measurement point (near the friction surface) can well reflect the temperature change of the friction surface.

The simulated temperature and the measured temperature of the near friction surface were compared and analyzed, and the relationship between friction temperature and friction torque was analyzed, as shown in Figure 10 and Table 2.

As shown in Figure 10, the temperature variation trend of the near friction surface obtained using simulation matches that measured by testing, with the simulated temperature slightly lower (less than $5^{\circ} \mathrm{C}$ ) than the measured temperature. This indicates that the temperature change of the iron-sulfur friction system was mainly controlled by friction heat, but with additionally heat sources in the system, which might include the heat released by the reaction of iron and sulfur to form iron-sulfide compounds. 


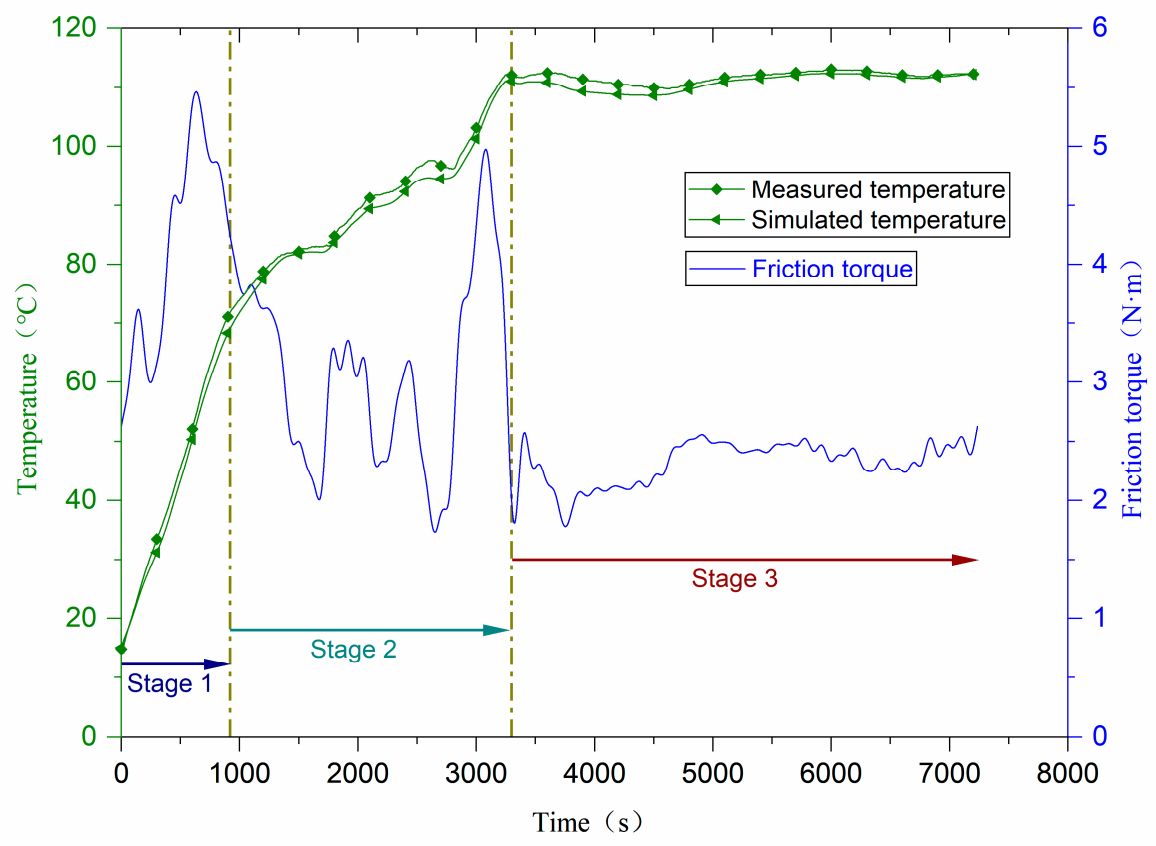

Figure 10. Measured and simulated temperature of near friction surface and friction torque of the test.

As indicated in Figure 10 and Table 3, there are three stages of the friction of ferroalloy and wet granulation sulfur under low normal load condition:

Table 3. The average temperature rise rate and the average friction torque of each stage.

\begin{tabular}{cccc}
\hline Stage & $\mathbf{1}$ & $\mathbf{2}$ & $\mathbf{3}$ \\
\hline Temperature rise rate $\left({ }^{\circ} \mathrm{C} / \mathrm{min}\right)$ & 3.750 & 1.026 & 0.003 \\
Friction torque $(\mathrm{N} \cdot \mathrm{m})$ & 4.156 & 3.088 & 2.138 \\
\hline
\end{tabular}

First stage: the friction medium of the test in this stage is the solid sulfur, causes poor lubrication between the friction surfaces. Therefore large quantities of friction heat generate in a short interval, the temperature near the friction surface increased rapidly. The average temperature rise rate and the average friction torque of this stage were respectively $3.750{ }^{\circ} \mathrm{C} / \mathrm{min}$ and $4.156 \mathrm{~N} \cdot \mathrm{m}$, respectively. During this stage, the average temperature of the friction surface was lower than the melting point of sulfur. However the friction heat will cause a sharp increase in the temperature of the true contact area [8-13], resulting in the melting of sulfur powders [27]. Due to the short duration of friction flash temperature, the molten sulfur will solidify again, the lubrication conditions were slowly improved.

Second stage: in this stage, the measured temperature was below $110^{\circ} \mathrm{C}$. Some of the sulfur had melted under the action of flash temperature in the 1st stage, the friction coefficient was reduced in this stage. The average friction torque of this stage was $3.088 \mathrm{~N} \cdot \mathrm{m}$, which was lower than that of the previous stage. As the friction coefficient decreased, the temperature rise rate of the friction surface in this stage was $1.026^{\circ} \mathrm{C} / \mathrm{min}$, which was also lower than that in the previous stage. The test then moved into the slow heating stage. As the temperature of the friction surface increased, there was more melting of sulfur on the friction surface, with further improved lubrication conditions of the friction surface in this stage.

3rd Stage: After $3300 \mathrm{~s}$ of friction, the temperature of the friction surface reached the melting point of sulfur. In this stage, a large amount of sulfur on the friction surface melted. As a result, the friction medium on the friction surface changed from solid sulfur powder to molten liquid sulfur, there was improved lubrication, the friction coefficient was further reduced, and the frictional heat was also reduced. The temperature remained almost constant and the average friction torque during this stage was $2.138 \mathrm{~N} \cdot \mathrm{m}$. The friction coefficient fluctuated within a certain range, the heat generation was 
basically stable. There was balance between heat generation and heat dissipation, and the temperature of the friction surface stabilized near the melting point of sulfur.

\subsection{Flash Temperature of Friction Surface}

It is assumed that the height distribution of the asperities on the friction surface of the friction specimens conformed to a Gaussian distribution. The average radius of the asperities on the friction surface was $10 \times 10^{-6} \mathrm{~m}$, with statistical parameters of $\mathrm{m}=0$ and $\sigma=1.0 \times 10^{-6}$, and the center line distance was $\mathrm{d}=0.5 \times 10^{-6} \mathrm{~m}$. The measured friction torque data and the established iron-sulfur friction flash temperature calculation model were used to calculate the variation of the flash temperature of the asperities with different peak heights on the friction surface with friction time, as shown in Figure 11.

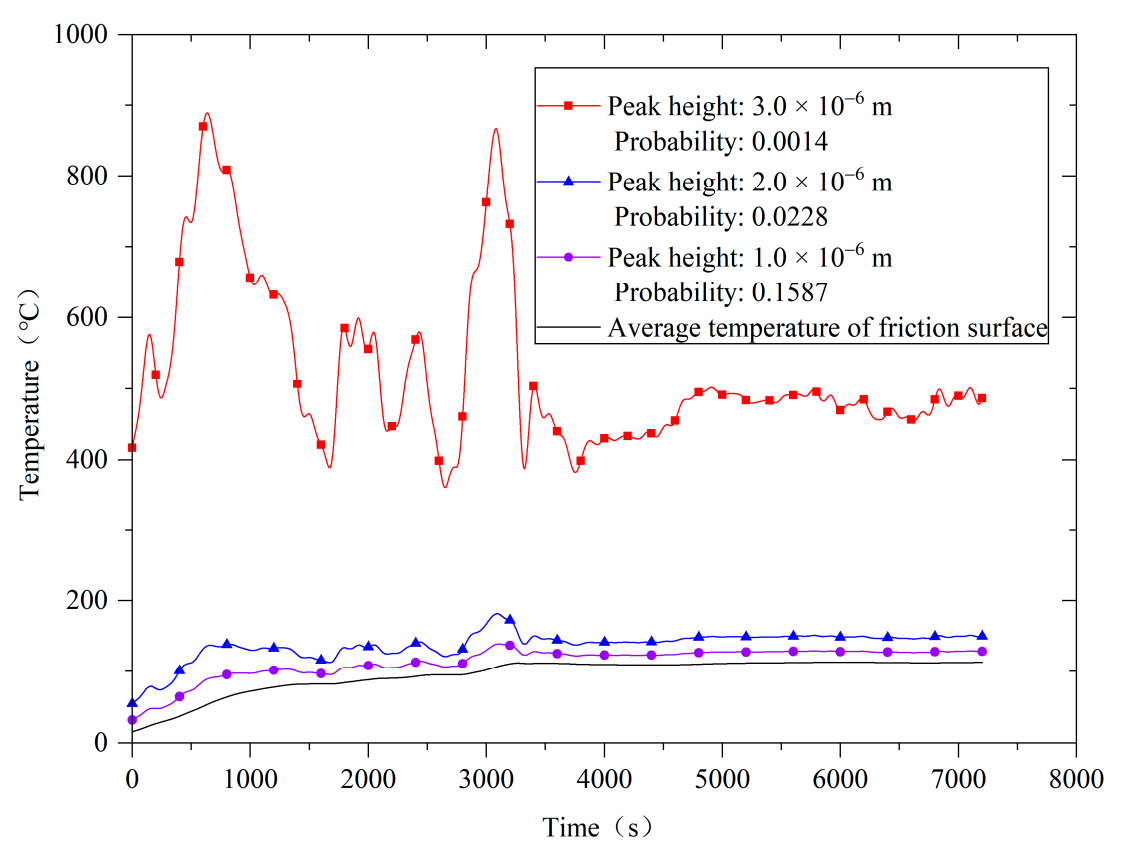

Figure 11. The friction flash temperature at different peak heights variation with time.

As shown in Figure 11, the flash temperature increased with the increase of the height of the asperities. For a peak height of $3.0 \times 10^{-6} \mathrm{~m}$, the maximum flash temperature of the asperities was almost $800^{\circ} \mathrm{C}$. The frictional flash temperature was always higher than $400^{\circ} \mathrm{C}$, much higher (more than $200^{\circ} \mathrm{C}$ ) than the average temperature of the friction surface during the entire friction process. Although this extremely high flash temperature has a low probability of occurrence and a short duration [11], the friction behavior between ferroalloy and wet granulation sulfur will be affected by this extremely high flash temperature during a long period of friction.

\section{Discussion}

In order to study the friction behavior of ferroalloy and wet granulation sulfur under low normal load conditions, an improved test apparatus was designed and different test specimens were examined. Based on the experimental data, calculation models of temperature field distribution of friction specimens and flash temperature on friction surface were established. The experiments and theoretical calculations allowed description of the friction behavior of ferroalloy and wet granulation sulfur under low normal load conditions. The flash temperature might sometimes reach $800^{\circ} \mathrm{C}$, which is much higher than the average temperature of the friction surface for ferroalloy and wet granulation sulfur under low normal load conditions. The temperature of the friction surface could change due to the direct reaction of iron and sulfur to form an iron sulfide compounds. Iron sulfur compounds were 
produced in a relatively short period of time $(0.5 \mathrm{~h})$, but iron sulfide compounds exhibited a slow formation rate. Considering only frictional heat as the heat source, the average temperature of the friction surface during the friction process was insufficient to reach the ignition point of sulfur. This supports the conclusions of previous research Ref. [7].

The temperature near the friction surface was below $70{ }^{\circ} \mathrm{C}$ in the initial stage (1st stage) as shown in Figure 4, Figure 9, and Figure 10, but the flash temperature of the friction surface could exceed $800^{\circ} \mathrm{C}$, as shown in Figure 11. In this high-temperature oxygen-isolating environment, iron-sulfide compounds will be generated via the reaction of sulfur and wear debris. The reaction process [5-7] may be expressed as Equations (14)-(17).

$$
\begin{gathered}
\mathrm{Fe}+\mathrm{S} \rightarrow \mathrm{FeS} \\
\mathrm{Fe}+2 \mathrm{~S} \rightarrow \mathrm{FeS}_{2} \\
\mathrm{FeS}+\mathrm{S} \rightarrow \mathrm{FeS}_{2} \\
\mathrm{FeS}_{2}+\mathrm{Fe} \rightarrow 2 \mathrm{FeS}
\end{gathered}
$$

Although the average temperature of the friction surface was lower than the melting point of sulfur in 1st stage, the friction flash temperature in the actual contact area was much higher than the melting point of sulfur (as shown in Figure 11). This would lead to melting of sulfur near the contact area. Due to the heat dissipation effect, this area of molten sulfur would solidify again. The lubrication conditions of the friction surface was slowly improved. With improved lubrication conditions, the friction coefficient decreased, the frictional heat decreased gradually, and the rate of temperature increase gradually decreased. In the 2nd stage the flash temperature on the friction surface could also reach $400{ }^{\circ} \mathrm{C}$, allowing the same chemical reaction to generate iron sulfide compounds.

It can be seen from Figure 9 that the temperature near the friction surface was lower than the average temperature of the friction surface. According to Figures 10 and 11, the average temperature of the friction surface increased gradually with time, and more and more sulfur melted on the friction surface. This further improved the lubrication condition, the frictional heat was reduced. Finally, when the amount of heat generated by friction was equal to the amount of heat dissipated, the temperature near the friction surface fluctuated within a certain range $\left(100-120^{\circ} \mathrm{C}\right)$ and then entered a stable stage (3rd stage). In this stage, the sulfur was almost completely melted, with more extensive contact with the friction specimens. The flash temperature of the friction surface at this time again exceeded $400{ }^{\circ} \mathrm{C}$, so the same chemical reaction as that in the 1st Stage and 2nd Stage would occur to generate iron sulfide compounds. With increased friction time, more iron-sulfide compounds were formed, which was consistent with the analysis and detection results presented in Figures 6-8. Previous work [28-31] showed that iron sulfide compounds can extremely easily undergo spontaneous combustion. This spontaneous combustion can occur when iron sulfide compounds generated by long-term friction are exposed to humid air. Therefore, amounts of iron sulfide compounds will be generated and accumulated after an extended period of friction between the sulfur powder and steel equipment in the transportation system of wet granulation sulfur. Combined with high air humidity and high surface temperature during the summer, the self-heating of iron-sulfide compounds becomes increasingly likely. Then the spontaneous combustion of iron sulfide compounds serves as the ignition source for the surrounding sulfur, thus explaining the friction ignition mechanism of the transportation system of wet granulation sulfur.

\section{Conclusions}

From the experimental, simulation, and theoretical calculation results, the following conclusions were drawn: 
1. During the friction of ferroalloy and wet granulation sulfur under low normal load conditions iron sulfide compounds were produced even in very short friction duration. However, the formation rate of iron sulfide compounds was very slow.

2. The simulated temperature as calculated by friction torque basically matched the measured temperature variation trend, which indicates that the temperature variation of this iron-sulfur friction system was mainly determined by the frictional heat.

3. The average temperature of the friction surface was slightly higher (less than $2{ }^{\circ} \mathrm{C}$ ) than that near the friction surface, but this temperature difference was not large and the temperature change trend was the same. Thus, the change of the average temperature in the friction surface could be assessed by monitoring the temperature near the friction surface.

4. The simulated temperature was slightly lower (less than $5^{\circ} \mathrm{C}$ ) than the measured temperature, which indicates the presence of other heat sources in the iron-sulfur friction system. This may include the exothermic reaction of iron and sulfur to form iron-sulfide compounds.

5. The friction flash temperature was much higher (more than $200^{\circ} \mathrm{C}$ ) at the asperities in the friction contact area than the average temperature of the friction surface. Although the occurrence probability of this extremely high flash temperature was low and the duration was short, the long-term friction process promoted the reaction of the ferroalloy and wet granulation sulfur to generate iron-sulfide compounds.

Author Contributions: Conceptualization, H.D. and J.F.; methodology, Y.Y.; software, L.S.; validation, Z.H. and J.G.; formal analysis, H.D.; investigation, H.D.; resources, H.D. and Z.H.; data curation, H.D. and Z.H.; writing —original draft preparation, H.D. and L.S.; writing—review and editing, J.F. and H.D.; visualization, Z.H.; supervision, J.F.; project administration, J.F.; funding H.D. and J.F.

Funding: This research was funded by Beijing Academy of Safety Engineering and Technology, Sinopec Dazhou Natural Gas Purification Plant and the Training Funded Project of the Beijing Youth Top-Notch Talents of China.

Acknowledgments: The authors are grateful to Sinopec Dazhou Natural Gas Purification Plant and Beijing Academy of Safety Engineering and Technology for the technical support to this work.

Conflicts of Interest: The authors declare no conflicts of interest.

\section{References}

1. Cheng, Y.; Wang, X. Study on Key Technology for Fire Control in Storage and Transportation of Bulk Sulfur. Petrochem. Saf. Environ. Prot. Technol. 2010, 26, 15-17.

2. Yu, Y.; Mao, H.; Pei, A. An analysis of key technologies applied in a super-large natural gas conditioning plant in the Puguang Gas Field. Nat. Gas Ind. 2011, 3, 22-25.

3. Cai, G.B.; Zhang, M.X.; Lin, L.Y.; Qin-Kun, X.U.; Chen, H.Y. Research on the grinding electrification characteristics of sulfur powder. J. Saf. Sci. Technol. 2011, 3, 26-30.

4. Fu, Y.; Lyu, Q.; Lyu, J.; Yang, Y.; Chen, H.Y.; Zhang, M. Electrostatic effect of sulfur powder grinding by ball mill. China Powder Sci. Technol. 2017, 3, 91-95.

5. Jiang, J.Z.; Larsen, R.K.; Lin, R.; Mørup, S.; Chorkendorff, I.; Nielsen, K.; Hansen, K.; West, K. Mechanochemical Synthesis of Fe-S Materials. J. Solid State Chem. 1998, 138, 114-125. [CrossRef]

6. Chin, P.P.; Ding, J.; Yi, J.B.; Liu, B.H. Synthesis of $\mathrm{FeS}_{2}$ and FeS nanoparticles by high-energy mechanical milling and mechanochemical processing. J. Alloys Compd. 2005, 390, 255-260. [CrossRef]

7. Dai, H.; Fan, J.; Wu, S.; Yu, Y.; Liu, D.; Hu, Z. Experimental study on ignition mechanisms of wet granulation sulfur caused by friction. J. Hazard. Mater. 2018, 344, 480-489. [CrossRef]

8. Bowden, F.P.; Hughes, T.P. Surface temperature of rubbing solids and the formation of the Beilby layer. Nature 1937, 139, 152. [CrossRef]

9. Bowden, F.P. Friction. Nature 1950, 166, 330. [CrossRef]

10. Archard, J.F. The temperature of rubbing surfaces. Wear 1959, 2, 438-455. [CrossRef]

11. Blok, H. The flash temperature concept. Wear 1963, 6, 483-494. [CrossRef]

12. Abdel-Aal, H.A. Flash Temperature Theory. Encycl. Tribol. 2013, 1182-1194. [CrossRef] 
13. Gao, J.; Lee, S.C.; Ai, X.; Nixon, H. An FFT-based transient flash temperature model for general three-dimensional rough surface contacts. J. Tribol. 2000. [CrossRef]

14. Ying, S.; Yupeng, Y. Temperature field analysis of pin-on-disk sliding friction test. Int. J. Heat Mass Transf. 2017, 107, 339-346. [CrossRef]

15. Chang, X.-D.; Peng, Y.-X.; Zhu, Z.-C.; Zou, S.-Y.; Gong, X.-S.; Xu, C.-M. Evolution Properties of Tribological Parameters for Steel Wire Rope under Sliding Contact Conditions. Metals 2018, 8. [CrossRef]

16. Wang, W.; Zhou, H.; Wang, Q.; Jin, J.; Sun, Y.; Wang, K. High-Temperature Tribological Behavior of the Ti-22Al-25Nb (at. \%) Orthorhombic Alloy with Lamellar O Microstructures. Metals 2018, 9, 5. [CrossRef]

17. Greenwood, J.A.; Williamson, J.B.P. Contact of Nominally Flat Surfaces. Proc. R. Soc. Lond. A Math. Phys. Sci. 1966, 295, 300-319.

18. Lai, L.; Gao, C.; Huang, J. Advances on sliding frictional contact models of rough surfaces. Chin. J. Constr. Mach. 2011, 2, 134-138.

19. Wen, S.; Huang, P. Principles of Tribology; John Wiley \& Sons: New York City, NY, USA, 2011. [CrossRef]

20. Yang, X.; Lu, Y.; Kangg, Y. Flash Temperature in the Process of Tool-rock Friction. J. Sichuan Univ. Sci. Ed. 2011, 43, 225-231.

21. Diez-Ibarbia AFernandez-del-Rincon, A.; de-Juan, A.; Iglesias, M.; Garcia, P.; Viadero, F. Frictional power losses on spur gears with tip reliefs. Frict. Coeff. Role Mech. Mach. Theory 2018, 121, 15-27. [CrossRef]

22. Pei, X.; Pu, W.; Zhang, Y.; Huang, L. Surface topography and friction coefficient evolution during sliding wear in a mixed lubricated rolling-sliding contact. Tribol. Int. 2019, 137, 303-312. [CrossRef]

23. Miler, D.; Hoić, M.; Domitran, Z.; Žeželj, D. Prediction of friction coefficient in dry-lubricated polyoxymethylene spur gear pairs. Mech. Mach. Theory 2019, 138, 205-222. [CrossRef]

24. Halliday, D.; Resnick, R.; Walker, J. Fundamentals of Physics; John Wiley \& Sons: New York City, NY, USA, 2013.

25. He, M.; Zheng, W.; Li, W.; Zhang, Y. Research on temperature distribution law around crack using the moving mode of eddy current thermography. Infrared Phys. Technol. 2019, 102, 102993. [CrossRef]

26. De Kraker, A.; van Ostayen, R.A.J.; Rixen, D.J. Calculation of Stribeck curves for (water) lubricated journal bearings. Tribol. Int. 2007, 40, 459-469. [CrossRef]

27. Greenwood, N.N.; Earnshaw, A. Chemistry of the Elements, 2nd ed.; Butterworth-Heinemann: Oxford, UK, 1997.

28. Amyotte, P.R.; Soundararajan, R.; Pegg, M.J. An investigation of iron sulphide dust minimum ignition temperatures. J. Hazard. Mater. 2003. [CrossRef]

29. Li, S.H.; Parr, S.W. The Oxidation of Pyrites as a Factor in the Spontaneous Combustion of Coal. Ind. Eng. Chem. 1926. [CrossRef]

30. Li, X.; Shang, Y.J.; Chen, Z.L.; Chen, X.F.; Niu, Y.; Yang, M.; Zhang, Y. Study of spontaneous combustion mechanism and heat stability of sulfide minerals powder based on thermal analysis. Powder Technol. 2017, 309, 68-73. [CrossRef]

31. Dou, Z.; Jiang, J.; Wang, Z.; Zhao, S.; Yang, H.; Mao, G. Kinetic analysis for spontaneous combustion of sulfurized rust in oil tanks. J. Loss Prev. Process Ind. 2014, 32, 387-392. [CrossRef]

(C) 2019 by the authors. Licensee MDPI, Basel, Switzerland. This article is an open access article distributed under the terms and conditions of the Creative Commons Attribution (CC BY) license (http://creativecommons.org/licenses/by/4.0/). 